\title{
Delimitar y gobernar las aguas de Lima: relaciones urbano-rurales y rivalidades administrativas en Lima colonial ${ }^{*}$
}

\author{
MARTHA BELL \\ Pontificia Universidad Católica del Perú \\ mbell@pucp.edu.pe
}

\section{RESUMEN}

En 1687 fue concluida la muralla de Lima, creando una frontera tangible entre el espacio urbano y rural. No obstante, mucho antes de esa fecha la división entre ciudad y campo ya habia sido establecida. Esto puede observarse en la forma de administrar el agua. Oficialmente, el agua de Lima y sus alrededores rurales estaba bajo la administración del Cabildo limeño. Sin embargo, el virrey y la Real Audiencia estuvieron frecuentemente envueltos en la administración hidráulica, a veces en directa confrontación con el Cabildo. Este artículo analiza el debate sobre los roles de estas instituciones durante todo el periodo colonial. Palabras clave: administración de agua, juez de aguas, Cabildo de Lima, Real Audiencia, relaciones urbano-rurales

* Este trabajo fue principalmente realizado gracias al auspicio del programa de posdoctorado Leiden Global Interactions, Universidad de Leiden, Holanda. Asimismo, agradezco a Gabriel Ramón por sus comentarios. 


\section{ABSTRACT}

Lima's city wall was completed in 1687, creating a physical boundary between the urban space and its rural surroundings. Yet well before this date, the division between city and countryside had been established. Water governance was one arena in which this can be observed. Officially, all water in Lima and its rural surroundings fell under the jurisdiction of Lima's Cabildo. However, the viceroy and Real Audiencia were also frequently involved in water governance, sometimes in direct conflict with the Cabildo. This article analyzes the debate over the roles of these branches of government during the entire colonial period. Keywords: water administration, water judge, Lima's Cabildo, Real Audiencia, urban-rural relations

$\mathrm{E}$ n 1648, el Cabildo de Lima expresó una opinión peculiar de forma unánime: «no admite separación lo de la ciudad a lo del campo y es preciso este todo en uno». ${ }^{1}$ Esta conclusión, sobre su visión de la administración de las aguas de Lima, no solo reflejaba una frontera porosa y poco delimitada entre la ciudad y el campo, sino además cierta tensión entre el Cabildo y la Real Audiencia asociada a la mala definición de los territorios bajo sus respectivas jurisdicciones. Esta opinión informaba sobre un conflicto de poder en la región de Lima. Los preceptos legales de la administración del espacio rural y de las aguas de riego que daban valor a esas tierras eran ambiguos y fueron cambiando durante el periodo colonial. Estas definiciones administrativas también implicaban relaciones con los indios residentes en esa zona y con su protector, quien fue uno de los participantes en el debate por las aguas. ${ }^{2}$ Algunos autores de fines del siglo XVIII — como Ambrosio Cerdán de Landa o Benito de la

1 Acta del Cabildo del 14 de enero de 1648, Archivo Histórico de la Municipalidad de Lima [en adelante AHML], Libros de Cabildos de Lima [en adelante LCL], volumen 23, f. 226. Los LCL originales, de 1535 a 1839, están en el AHML. Para los libros de 1535 a 1639 hemos empleado la versión paleografiada y editada por Lee y Bromley (1935-1962); para los de 1639 a 1705, los originales.

2 El protector de indios fue un administrador bajo la autoridad del rey y era responsable de defender y representar a las poblaciones indígenas en las cortes españolas. El puesto 
Mata Linares - sostienen que las discusiones para resolver esta confusión comenzaron en $1780,{ }^{3}$ pero enseguida mostraremos que este conflicto fue mucho más antiguo, pues comenzó a inicios del régimen colonial y pasó por distintas etapas antes del debate de fines del siglo XVIII.

En este artículo examinaremos la historia urbana limeña considerando la porosa y cambiante frontera entre el espacio urbano y el espacio rural, concentrándonos en los flujos de agua que los entrecruzaban y las rivalidades entre las autoridades para controlarla. Presentaremos y analizaremos tres contextos o casos de estudio en los que se discutía este tema: 1) el territorial, o la definición legal de los términos de la ciudad; 2) el jurisdiccional, o el mandato real de la administración del agua; y 3) la rivalidad u oposición entre el Cabildo y la Real Audiencia en el manejo cotidiano del agua. Basaremos este análisis en tres tipos de documentos: las Leyes de Indias y cédulas reales relevantes para Perú y Lima; los Libros de Cabildos de Lima (en adelante LCL); y la colección del Juzgado de Aguas de Lima depositada en el Archivo General de la Nación (en adelante AGN). De este modo, documentaremos y discutiremos la definición de la zona urbana y de la jurisdicción de aguas desde la fundación de la ciudad hasta el fin de la época colonial.

\section{Preguntas y metodología}

Los trabajos previos sobre la historia del uso y manejo del agua en Lima colonial se han enfrentado ocasionalmente con un detalle complicado: si bien el Cabildo nombraba anualmente un juez de aguas para la ciudad y el campo, los documentos más importantes sobre el reparto de aguas de riego fueron firmados por hombres llamados «juez de aguas de la Real Audiencia». Por ejemplo, los conocidos textos de Juan de Canseco y Ambrosio Cerdán de Landa fueron elaborados por jueces de aguas nombrados por la Real Audiencia y no por el regidor elegido juez de

fue creado en 1591 y su labor era, sobre todo, defender a los indígenas de las demandas de los encomenderos. Véase Borah 1985: 22; y Lohmann 2001: 54.

3 Para el proyecto de Mata Linares, véase Domínguez 2015. 
aguas del Cabildo. ${ }^{4}$ Otros trabajos también se han interrogado sobre este doble nombramiento, ${ }^{5}$ por lo cual ha surgido un interés por explicar a qué se debería esta duplicidad, cómo funcionaba cotidianamente y cómo se solucionaba (o no) el conflicto.

En este artículo trataremos de aclarar este punto, aplicando las tres estrategias mencionadas. La primera es examinar las Leyes de Indias, las ordenanzas de los virreyes, las cédulas reales y otros documentos que registran mandatos legales relacionados al agua y su administración. La segunda es analizar en detalle las menciones al agua en los LCL — sobre todo las referidas al agua rural o de riego - para mejor comprender el rol del Cabildo en la administración de las aguas rurales. La tercera consiste en revisar los documentos hechos por los jueces de aguas nombrados por la Real Audiencia, algunos publicados — como los de Canseco (1617), Mata Linares (1780) o Cerdán de Landa (1793) — y otros en la colección del Juzgado de Aguas del AGN, para compilar una lista de jueces de aguas nombrados por la Real Audiencia y explicar cuáles fueron sus responsabilidades. En esta enorme colección documental nos centraremos en los textos vinculados a las disputas y discusiones entre el Cabildo, la Real Audiencia, el virrey y el protector de indios sobre quién debería administrar las aguas rurales, especialmente utilizando los casos de los años 1628, 1631, 1648, 1671 y 1672, y haciendo referencia a algunos eventos más tardíos de 1780 y 1804 . Desde una perspectiva metodológica, la identificación de estos conflictos solo ha sido posible gracias a la revisión exhaustiva de los LCL. ${ }^{6}$ Este análisis nos da una cronología maestra de la ciudad: un marco para poner en contexto los

4 El texto de Juan de Canseco, «Repartimiento del Agua del Rio grande de esta Ciudad por el Señor Doctor Don Juan de Canseco» fue publicado, con un estudio detallado, en Domínguez 1988. Véase, además, Cerdán de Landa 1793.

5 Más recientemente, Domínguez 2015 y Cogorno 2015: 58-60.

${ }^{6}$ Nuestro análisis de los LCL incluye la revisión de todos los libros del siglo XVI y XVII, para identificar y fichar las referencias relacionadas con la administración del agua. En cuanto al siglo XVIII, la metodología fue modificada para hacer búsquedas solamente en periodos específicos. La mayoría de este trabajo fue realizado para el proyecto «Arqueología hidráulica colonial: autoridades, infraestructura y redes políticas (Lima, 1535-1796)», financiado por una beca de investigación del Instituto Riva-Agüero (2011) 
casos de interés. Con este objetivo, utilizaremos también a Cerdán de Landa en su capacidad de historiador del agua limeño.

\section{«TIERRA SANA Y FÉRTIL Y ABUNDANTE DE AGUA»: LA FUNDACIÓN DE LIMA EN PERSPECTIVA HIDRÁULICA}

La ciudad de Los Reyes fue fundada en el año 1535 al borde meridional del río Rímac. Esta ubicación no fue casual, pues los españoles, en el Perú en general, buscaban sitios caracterizados por ser «tierra sana y fértil y abundante de agua y leńa, y buenos pastos para ganados».7 Desde el principio, el Rímac moldeó el desarrollo urbano. Como nos cuenta Cieza, la ciudad se fundó al borde del río, lo cual le sirvió como frontera y limitó su crecimiento hacia el norte y noreste. ${ }^{8} \mathrm{~A}$ su vez, fue clave para sostener las necesidades de la ciudad: agua de riego para los campos, agua para beber y cocinar, agua de limpieza e higiene, agua para la fuerza motriz de molinos e ingenios y más. ${ }^{9}$

Las características fluviales del Rímac impactaron en la vida diaria de los limeños. Este río, nacido en los altos Andes, exhibía una fuerte estacionalidad asociada a las lluvias y nevados serranos. Estaba casi seco entre mayo y septiembre, meses durante los cuales los canales y las acequias podrían dejar de fluir, interrumpiendo los molinos y poniendo en riesgo los cultivos, pero también haciendo posible limpiar y mantener las acequias y bocatomas y construir y componer los tajamares a orillas del río. Estos tajamares tenían que estar listos para octubre, cuando el río se llenaba y empezaban a llegar fuertes crecidas en su flujo, las llamadas

y con la participación de tres investigadores responsables: Martha Bell, Gilda Cogorno y Gabriel Ramón. Los asistentes del proyecto fueron Marcos Alarcón y Moisés Cueva. 7 «Instrucciones al virrey del Perú para hacer nuevos descubrimientos y poblaciones» (Solano 1996, I: 158-162). Este es un mandato para la formación de núcleos urbanos en el Perú, hecho en 1556, después de la fundación de Lima, y solo usado aquí como idea general.

8 Cieza de León 1984: 283-285.

9 Los molinos horizontales fueron utilizados para moler granos, mayormente trigo. Los ingenios fueron máquinas hidráulicas utilizadas para diversos fines, como moler cobre y hierro y aserrar madera (Acta del Cabildo del 14 de noviembre de 1670, AHML, LCL, volumen 29, ff. 43v-44). 
avenidas. Estas continuaban por todo el verano costeño, hasta abril. ${ }^{10}$ Aunque esta crecida estacional del río podía ser peligrosa para la ciudad y las bocatomas de las acequias grandes, también era bienvenida para el ciclo agrícola.

Mapa 1. Vista general de la región de Lima, con el río Rímac $\mathrm{y}$ las acequias de riego

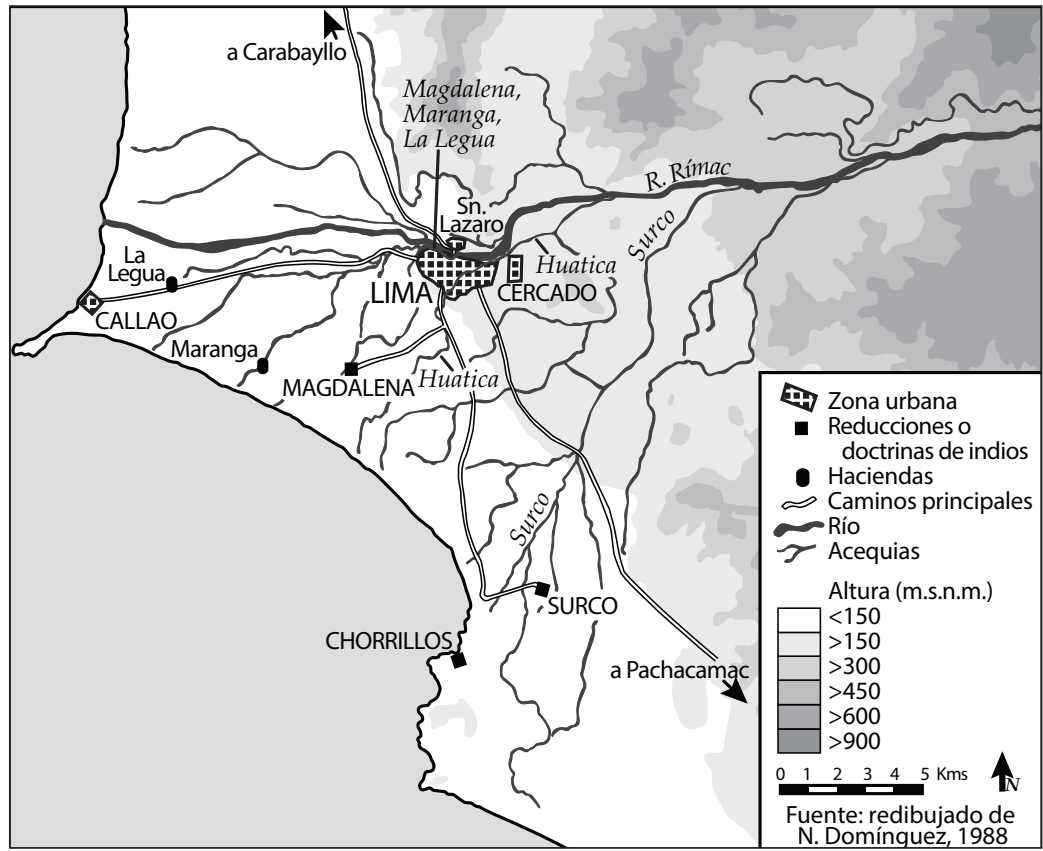

Dos de estas acequias atravesaron el centro urbano: la de Huatica y la que luego se repartía hacia Magdalena, Maranga y La Legua (pasaba por una pequeńa parte de la zona urbana, en el extremo noroeste de la ciudad). La acequia de Surco no cruzaba la zona urbana, pero fue de mayor importancia para la agricultura. El mapa no incluye las acequias menores que entrecruzaban la ciudad. 
Las acequias, llamadas ríos, derivadas del Rímac fueron fundamentales para la producción agrícola de toda la región. ${ }^{11}$ Diecisiete valles regados por estos ríos se encontraban desde las zonas más altas, como Naña, hasta las más bajas, como La Legua (mapa 1). Algunos de ellos — posiblemente la mayoría - tuvieron un origen precolonial, ${ }^{12}$ pero el sistema de producción agrícola fue dominado por las introducciones europeas:

Fuera de la ciudad, a una parte y a otra, hay muchas estancias y heredamientos, donde los españoles tienen sus ganados y palomares, y muchas viñas y huertas muy frescas y deleitosas, llenas de las frutas naturales de la tierra, y de higuerales, platanales, granados, cañas dulces, melones, naranjos, limas, cidras, toronjas y las legumbres que se han traído de España; todo tan bueno y gustoso que no tienen falta antes digno por su belleza $[\ldots]$ verdaderamente es una de las buenas tierras del mundo. ${ }^{13}$

Lima fue una zona fértil, con una producción agrícola diversificada y con mucha importancia para la economía local y regional.

Además, como sucede en casi todas las cuencas del mundo, la del Rímac fue un espacio que incorporaba múltiples usos del agua en simultáneo, algunos en concordia, algunos en conflicto. El conflicto mayor fue cómo repartir adecuadamente el agua entre los diversos campos agrícolas, los cuales incluían haciendas, chacras de escala pequeña o intermedia, tierras controladas por órdenes religiosas y territorios indígenas. Fue imprescindible ordenar el uso de agua de las acequias madres (los ríos). En la época colonial, esta tarea estaba a cargo del juez de aguas de Lima y se hacía a través de un sistema de reparto de riegos, en el cual cantidades fijas de agua se dejaban fluir por tiempos asignados para irrigar las chacras o tierras de cada propietario. En teoría, este tipo de sistema protegía los derechos de todos los usuarios de las acequias. Por ejemplo, si alguien que tenía tierras cerca de la bocatoma usaba más agua de la que le correspondía, dejaría desabastecidos a los usuarios ubicados en la parte media o al final de las acequias. Algunos de estos usuarios se

\footnotetext{
${ }^{11}$ Domínguez 1988; este trabajo incluye un mapa muy útil de estas acequias.

12 Narváez 2013.

13 Cieza 1984: 284.
} 
ubicaban dentro del centro urbano (por ejemplo, los molineros de la ciudad, quienes necesitaban que les llegara un flujo hidráulico fuerte) y otros se encontraban en zonas rurales al lado oeste, o aguas abajo de la ciudad (por ejemplo, los agricultores de Magdalena, Maranga, La Legua y alrededores que necesitaban que el agua pasara a través de la ciudad para recién llegar a sus tierras). Por ello era necesario que algunas de las acequias cruzaran la ciudad sin que se interrumpieran sus rutas. Así, los planos tempranos de Lima muestran estas acequias entrando y saliendo de la ciudad. ${ }^{14}$

En la práctica, sin embargo, el sistema de reparto hidráulico no funcionó perfectamente ni fue fácil de administrar. Había mucho desorden, y hasta conflictos que incluían acciones de violencia — «rencillas y cuchilladas»— asociadas a la distribución del agua. ${ }^{15}$ Además, parece que en cada valle y zona había distintos guardianes escogidos por los usuarios para vigilar el sistema de reparto. Domínguez ha explicado que este sistema estaba basado en "formas y prácticas tradicionales», en lo que podría denominarse «un 'derecho consuetudinario' basado en privilegios y preeminencias» o más simplemente "colonial tradicional». ${ }^{16}$ Este sistema cotidiano de administración y resolución de conflictos debe ser estudiado con más detalle, ya que todavía lo conocemos muy poco. En ese sentido, para poder reconstruir el sistema colonial tradicional, partiremos de la hipótesis de que este se habría formado debido a dos ambigüedades legales: una relacionada con el manejo del territorio y otra con la rivalidad entre las autoridades coloniales.

${ }^{14}$ Por ejemplo, Bernardo Clemente Principe, «Planta de la muy yllustre ciudad de Los Reyes corte del reino del Peru», 1674, Library of Congress Geography and Map Division, Washington, D. C.

${ }^{15}$ Ordenanzas de Toledo citadas en Domínguez 1988: 130.

${ }^{16}$ Domínguez 2015. 
AMBIGÜEDADES TERRITORIALES Y LEGALES EN LA ADMINISTRACIÓN DEL AGUA

\section{Primera ambigüedad: los términos de la ciudad}

Mientras fundaban la ciudad y empezaban a remodelar el sistema hidráulico de sus alrededores, los colonizadores españoles implementaron un sistema de gobierno para administrar la región. Como en todas las ciudades y villas o pueblos grandes, en Lima se formó un Cabildo, compuesto por doce regidores y dos alcaldes ordinarios. Este órgano de gobierno, en Lima como en otros lugares, se preocupaba por muchas de las necesidades urbanas. Esto incluía, entre otras cosas, el planeamiento urbano, las concesiones de tierras y solares dentro de la ciudad, el control del comercio, la provisión de comida y otros productos, el manejo de recursos naturales, como pastos y leña, y la administración hidráulica. ${ }^{17}$ Con respecto a este último punto, el Cabildo tenía la autoridad de repartir derechos al agua de beber y de riego, y también la responsabilidad de construir y mantener la infraestructura necesaria para utilizarla. ${ }^{18}$ Desde 1535 hasta 1839 , con pocas interrupciones, los LCL registraron fielmente las actividades administrativas de esta institución, por lo que son una fuente de información fundamental para entender su labor.

Desde inicios del régimen colonial, se discutió sobre el área o territorio bajo el control del Cabildo. Los términos de la ciudad, o «la porción de territorio sometido a la autoridad de un ayuntamiento", ${ }^{19}$ variaban con el tamaño e importancia de esta, pero típicamente incluían un radio de aproximadamente veinte leguas alrededor del centro de la ciudad: su plaza Mayor. Testimonios del siglo XVI indican que «al tiempo que tuvo principio y se fue aumentando esta tierra, con habitación de espańoles, se le señalaron a esta dicha ciudad [Lima] más de cuarenta leguas, por distrito de su jurisdicción». ${ }^{20}$ Sin embargo, en 1596, el regidor Martín

${ }^{17}$ Para una descripción del Cabildo y sus trabajos, véase Moore 1954.

${ }^{18}$ Véase Bell 2015.

${ }^{19}$ Definición de la Real Academia Española (RAE).

20 «Carta escrita por Martín de Ampuero, al don García Hurtado de Mendoza, marqués de Cañete, virrey, Los Reyes, 8 de marzo 1596» (Solano 1966, I: 269-270). Una legua equivalía aproximadamente 5,56 kilómetros. 
Mapa 2. Los términos de la ciudad en tres periodos

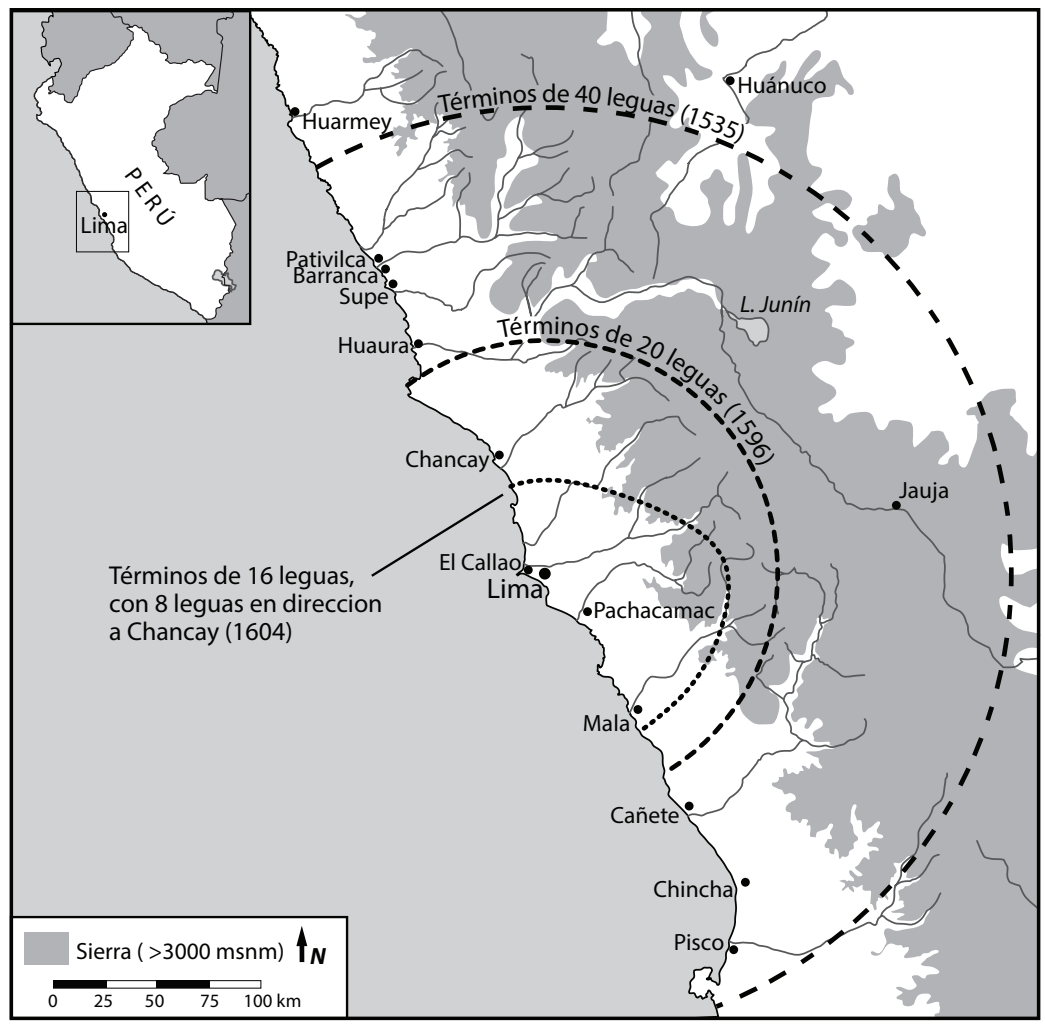

Alonso de Ampuero presentó una petición al virrey, el cuarto marqués de Cañete (1590-1596), para asignar a la ciudad de Lima «veinte leguas de jurisdicción alrededor de la comarca» ${ }^{21}$ (mapa 2). En este caso, el virrey señaló las dichas veinte leguas —aproximadamente 110 kilómetrosagregando que esto no debería causar conflictos con las jurisdicciones de los «tambos» de Cañete y Arnedo (Chancay), ya que estos lugares estaban incluidos dentro de este radio, o cerca de la frontera. Ocho años después, en 1604, el territorio bajo la jurisdicción de la ciudad fue reducido por segunda vez, cuando el virrey don Luis de Velasco 
(1596-1604) determinó que los términos comprendieran tan solo ocho leguas en dirección a Chancay (aproximadamente 44 kilómetros, hasta donde hoy está Ancón) y dieciséis en el resto de su contorno (más o menos hasta donde se ubica Mala). Dentro de este territorio, el virrey mantenía su propia jurisdicción sobre los asuntos indígenas..$^{22}$ Así, son dos los patrones que se pueden observar. Primero, la disminución del territorio bajo el control del Cabildo limeño. Y, segundo, la ambigüedad del mandato establecido dentro del territorio respecto a las relaciones con los otros pueblos cercanos y los indios.

En resumen, los términos de la ciudad evolucionaron a lo largo de tres periodos: el fundacional (40 leguas), el del gobierno del virrey marqués de Cañete (20 leguas) y el del gobierno del virrey don Luis de Velasco (16 leguas, con 8 leguas en la dirección de Chancay). Una legua equivalía aproximadamente 5,56 kilómetros.

\section{Segunda ambigüedad: el cargo de juez de aguas}

La administración de las aguas dentro de los términos de la ciudad era una de las responsabilidades más atractivas y complejas para los regidores, ya que era imprescindible para la vida y la producción agrícola en la zona e implicaba proteger los intereses de diversos grupos sociales y negociar entre múltiples usos. Aunque algunos autores han tratado de mostrar la conexión entre la administración colonial temprana y las tradiciones indígenas de la zona, ${ }^{23}$ aquí vamos a comenzar por las Leyes de Indias que indicaban que todas las aguas de los dominios coloniales españoles eran propiedad comunal. Para poder utilizar el agua, los potenciales usuarios debían contar con títulos o licencias de un órgano de gobierno. ${ }^{24}$ En el siglo XVI, el Cabildo - la institución con más poder en la zona y, se podría decir, la única en Lima realmente existente y presente en el periodo temprano- fue el órgano que repartía y administraba estas aguas.

22 «Provisión de don Luis de Velasco, virrey de Perú, Los Reyes, 27 de abril de 1604» (Solano 1996, II: 28).

${ }^{23}$ Véase Cogorno 2015: 44-45, 51-54; y también Domínguez 1988: 128.

${ }^{24}$ Recopilación de leyes 1791, II: 41 y 57; véase discusión en Bell 2015: 80-81. 
En 1556, por mandato del virrey, segundo marqués de Cañete (15561560), el primer juez de aguas de Lima fue nombrado para administrar las aguas de la ciudad y sus términos. Este juez fue el regidor y capitán Martin Yáñez de Estrada, con un salario de 800 pesos y responsabilidades que claramente incluían la administración de las aguas de la ciudad y las acequias de riego del campo. Uno de sus trabajos centrales era la distribución de aguas entre españoles e indígenas, para evitar conflictos. ${ }^{25}$ En 1557, el Cabildo pidió, y el virrey concedió, que «concluido el año de judicatura por Martin Yáñez, pudiese anualmente nombrar para ella sucesivamente con el mismo salario asignado». ${ }^{26}$ Once años más tarde, en 1568, este nombramiento o elección se formalizó plenamente, cuando Felipe II concedió una real cédula, dirigida a la Real Audiencia de Lima, confirmando la necesidad de nombrar anualmente un juez de aguas — «siendo todos los Llanos de la Capital y sus términos, tierras de regadío»- para cuidar la zona y proteger los derechos de los indígenas. La real cédula aclaró «que se mantubiese al Cabildo en el libre uso de tal nombramiento». ${ }^{27}$ Entonces, el Cabildo comenzó a elegir, entre sus regidores, a un juez de aguas anualmente, en enero, para la ciudad y el campo.

Este sistema de nombramiento empleado por el Cabildo funcionó más o menos bien entre 1556 y 1577, cuando el virrey Francisco de Toledo trató de hacer algunos cambios en el Juzgado de Aguas y la administración de aguas en general. ${ }^{28}$ Además de sus detalladas ordenanzas para la limpieza y el mantenimiento de las acequias urbanas y rurales, Toledo instituyó los cargos de ejecutores de las ordenanzas de las aguas — uno para el campo y otro para la ciudad-, eliminando el cargo de juez de aguas. ${ }^{29}$ Ambos funcionarios iban a ser nombrados por

\footnotetext{
${ }^{25}$ Cerdán de Landa 1793: 9-11; Domínguez 1988: 127, y Cogorno 2015: 55-57.

${ }^{26}$ Cerdán de Landa 1793: 10; sobre esta formalización, véase Cogorno 2015: 57-58.

27 Cerdán de Landa 1793: 4; y Domínguez 1988: 129.

${ }^{28}$ Sin embargo, hubo varias quejas de abusos a los indígenas y también de la incompetencia de los jueces (véase Cogorno 2015: 56-60); sobre todo, entre 1561-1564, cuando por primera vez se nombraron dos jueces de aguas, uno para la ciudad y otro para el campo. ${ }^{29}$ Las ordenanzas de aguas del virrey Toledo fueron promulgadas en Lima, el 21 de enero de 1577; véase Toledo 1986-1989, II: 275-285.
} 
el Cabildo; sin embargo, este sistema solamente funcionó unos tres o cuatro años y, en 1581, ya se había vuelto al nombramiento tradicional del juez de aguas. Posteriormente, en 1620, el Cabildo expresó una queja contra el nombramiento de Diego Núñez de Campoverde como juez de aguas por el virrey príncipe de Esquilache (1615-1621). Nuñez no era regidor ni había sido elegido por el Cabildo, por lo cual una real cédula de 1621 reconfirmó la de 1568 y ordenó a la Real Audiencia dejar que el Cabildo siguiera con "la costumbre entablada» de nombrar al juez de aguas. ${ }^{30}$ Después de este momento, cada año, hasta la época republicana —-más de 200 años — el Cabildo nombró un juez de aguas para la ciudad y el campo, con raras excepciones que serán discutidas en la siguiente sección. ${ }^{31}$

Para complejizar el panorama presentado, cabe indicar que las ordenanzas de las reales audiencias de 1563 sobre la repartición de aguas, pastos, tierras y solares, indicaban que el trabajo de hacer estas importantes divisiones era privilegio del presidente y los oidores de aquellos tribunales. Sin embargo, estas ordenanzas estipularon, que en caso de ciudades que ya contaban con Cabildos, estos repartos se debían hacer «con parecer de los cabildos de ellas, teniendo respecto que en los tales repartimientos sean preferidos los regidores de ella [...] y que los tales repartimientos se hagan sin perjuicio de los indios». ${ }^{32}$ En el caso del reparto de aguas y tierras para ingenios, se debían presentar peticiones al presidente de la Real Audiencia (generalmente el virrey), pero él debía enviarlas al Cabildo para que este tomara una decisión y luego remitiera su parecer a la Real Audiencia. Además, las ordenanzas concluían indicando que el presidente y los oidores de la audiencia debían nombrar

un juez que reparta las aguas a los naturales por el tiempo que la necesidad durare, cada vez que fuere necesario [...] y tendrán mucho cuidado los dichos

${ }^{30}$ Cerdán de Landa 1793: 12; y Domínguez 1988: 129-130.

${ }^{31}$ Para listas de los jueces de aguas nombrados por el Cabildo, véase, para el siglo XVI, el Anexo 5 de Cogorno 2015 y, para el siglo XVII, el Apéndice C de Bell 2013. No hay datos publicados para los siglos XVIII y XIX, pero para este estudio la autora empleó listas elaboradas por Alex Loayza y Gabriel Ramón a quienes agradece por compartir sus datos. 32 «Ordenanzas de las reales audiencias, 1563» (Solano 1986-1989, I: 175). 
nuestros oidores no enviar por causas livianas receptores a los pueblos de indios, ni a otra parte, si no fuere sobre cosas de importancia que convenga mucho enviarlos. ${ }^{33}$

En consecuencia, desde 1611, hubo una serie de nombramientos ocasionales de un juez de aguas realizados por la Real Audiencia (cuadro 1). Entre ellos estuvo el famoso doctor Juan de Canseco, un alcalde de corte de la Real Audiencia nombrado por el virrey príncipe de Esquilache en 1617 para hacer una justa distribución de las aguas del Rímac. Entonces podemos identificar una segunda ambigüedad, esta vez entre la jurisdicción del Cabildo y la de la Real Audiencia. Parece que en casos especiales, sobre todo cuando había problemas con el agua de los indígenas, la Real Audiencia podía intervenir en el reparto de aguas, lo cual en tiempos normales debía ser trabajo del Cabildo.

\section{EXPERIMENTOS CON LOS LÍMITES: SEPARANDO E INTEGRANDO LAS} AGUAS URBANAS Y RURALES

Las dos ambigüedades anteriormente indicadas, junto con la importancia de las aguas de riego, fueron la base de una estructura permanentemente inestable, que de vez en cuando estallaba en discusiones o conflictos abiertos sobre quién tenía la jurisdicción sobre las aguas rurales. Aunque en teoría era el Cabildo, y así lo indicaban sus miembros, en la práctica, muy pocas reuniones del ayuntamiento municipal incluían discusiones sobre las aguas rurales. En el siglo XVII, por ejemplo, hay menos de veinte menciones de acequias de riego en los LCL, mientras sí se preocupaban con mucha frecuencia de las aguas urbanas. ${ }^{34}$ En la colección del Juzgado de Aguas del AGN existen pocos casos adicionales del siglo XVII (alrededor de 10) en los cuales el juez de aguas era miembro del Cabildo y se encontraba trabajando en la zona rural con acequias de riego. Esta situación concreta, que el juez de aguas del Cabildo no trabajara tanto como debería en el campo, fue una causa recurrente de discusión.

${ }^{33} \mathrm{Ib}$.

${ }^{34}$ Bell 2015: 78 . 
Algunos casos del siglo XVI muestran que este fue un punto difícil desde los primeros años en que se nombraba jueces de aguas. Gilda Cogorno identifica por lo menos siete experimentos para dividir el cargo entre dos (o múltiples) personas entre 1568 y $1600 .{ }^{35}$ La división propuesta en las ordenanzas de la ciudad y del campo y sus respectivos ejecutores dirigida por el virrey Toledo es la más conocida de estos casos. Es notable que ninguno de estos intentos de división durara más que un par de años. Concordamos con Cogorno cuando sugiere que estas divisiones se dieron en momentos de crisis o fuerte competencia entre el Cabildo y el virrey.

En enero de 1628, el protector de indios explicó la situación general del sistema hidráulico limeño en una petición o queja presentada al virrey con copia al Cabildo:

Exelentisimo señor El protetor general de los naturales deste rreyno por los de los pueblos de la madalena surco y late diçe que a su notiçia es benido que algunos labradores espańoles an pedido ante Vuestra exelençia se sirba de nonbrar un Juez de aguas que no sea del Cabildo desta çiudad conforme a la ordenança del señor don françisco de toledo [...] lo que an pedido los dichos labradores y por lo que a los dicho pueblos de indios toca se a de servir Vuestra Exelençia de nonbrar un Juez de aguas del canpo por los muchos ynconbinientes que an rresultado de que lo sean los del dicho Cabildo y sus rregidores por la mucha ocupaçion que tienen en las açequias desta çiudad que apenas pueden acudir al rreparo dellas/ lo otro por ser como son los mas de los dichos rregidores haçendados en el canpo y de las mayores sementeras que se cojen en estos balles haçen muchos agrabio y bejaciones quitando el agua que quieren a los demas labradores y en espeçial a los yndios de los dichos pueblos que tantos años ha claman y rrepresentan en el gobierno y en la rreal audiençia que por ser su execuçion por mano de los dichos Juezes de agua no tiene efecto alguno por ser en propia causa y contra sus mesmos conpañeros y que otro año an de procurar hagan lo mesmo con ellos lo otro el dicho Cabildo no tiene çedula de su magestad para nonbrar los dichos Juezes de agua en el canpo y ansi no la a presentado en el gobierno como debiera y en caso que la tenga suplico de la dicha rreal cedula para que con el debido rrespecto no tenga su cumplimiento atento a las justas causas rreferidas. ${ }^{36}$

\footnotetext{
${ }^{35}$ Cogorno 2015: 60.

${ }^{36}$ Acta del Cabildo del 1 de enero de 1628 (Lee y Bromley 1935-1962, 21: 6-7). Los LCL registraban varias quejas hechas por la Real Audiencia sobre los problemas que tuvo el Cabildo en cuidar las acequias de la ciudad. Por ejemplo, Acta del Cabildo del 13 de
} 
Esta notable descripción tiene tres puntos importantes que merecen discusión. Primero, el protector comenta las dificultades que tenía el Cabildo para manejar las aguas de la ciudad, indicando que este órgano del gobierno municipal debería concentrarse en la zona urbana, su ámbito apropiado. Segundo, el protector de indios pide que, para las aguas rurales, el virrey nombre un juez de aguas que no sea del Cabildo, puesto que hacerlo había provocado muchos problemas en ańos anteriores. El protector argumentaba que estas dificultades se debían a que los propios regidores del Cabildo eran dueños de las haciendas necesitadas de agua. Entonces, ellos mismos aprovechaban la mayor cantidad de agua, perjudicando a los indios y otros agricultores. Como el cargo de juez de aguas rotaba entre los regidores, ninguno de ellos tenía un real interés en hacer cumplir las ordenanzas o proteger los derechos de los demás usuarios de agua, ya que no querían contradecir a sus colegas por miedo de resultar posteriormente perjudicados. Corroborando esta observación, varios documentos del Juzgado de Aguas del AGN tratan sobre jueces de aguas interviniendo en casos del uso de agua en las haciendas de los regidores.

Tercero, el protector se refiere a varias ambigüedades y faltas en la legislación hidráulica. Alude a la ordenanza del virrey Toledo, indicando que en ella se señala que el juez de aguas debería ser nombrado por la Real Audiencia. Además, da a entender que no existe una real cédula que ordene explícitamente al Cabildo nombrar al juez de aguas.

Esta petición fue supuestamente dirigida al virrey el marqués de Guadalcazar (1622-1629). Sin embargo, tras su renuncia y muerte, la resolución del conflicto tuvo que aguardar algunos años. En 1631, en respuesta al pedido del protector de indios, el nuevo virrey, el conde de Chinchón (1629-1639), hizo pública una nueva real cédula donde se indicaba «que se elija en el dicho ofiçio de Juez de aguas persona que no sea ynteresada en el agua y de satisfaçion y confiança que no consienta

agosto de 1607 (Lee y Bromley 1935-1962, 15: 462-463). El documento no indica el nombre del protector, pero posiblemente fue Domingo de Luna; véase Lohmann 2001: 193. 
haçed agrabios a los yndios en que se les toma el agua». ${ }^{37}$ Desde 1632 y por el resto del siglo XVII, esta cédula fue anualmente leída en el Cabildo antes de la elección del juez de aguas. Esta situación legal fue confirmada en 1646, cuando algunos capitulares protestaron el nombramiento de Diego Bermúdez de la Torre, reclamando que él tenía chacras regadas con el río Surco. ${ }^{38}$ En general, con la petición del protector de indios y su resolución, podemos ver las posiciones de las distintas autoridades coloniales. El protector de indios tuvo que negociar con el virrey, quien a su vez podía enviar instrucciones al Cabildo, aunque al final muy poco cambiaba y la situación se mantenía básicamente igual: el Cabildo nombraba el juez de aguas para la ciudad y el campo.

La tensión entre las aguas de la ciudad y el campo reapareció en 1648 cuando el virrey marqués de Mancera (1639-1648) sugirió al Cabildo nombrar dos jueces de aguas, uno para el campo y otra para la ciudad. ${ }^{39}$ El Cabildo respondió: «aviendosse conferido sobre ello hallaron todos los dhos alcaldes y capitulares que es de muy grande ynconveniente que aya dos Juezes de aguas por que no admite sseparaçion lo de la çiudad a lo del campo y es preçiso este todo en uno». ${ }^{40}$

Tomando en cuenta esta opinión, el virrey aprobó la decisión del Cabildo y se procedió a elegir a Bartolomé de Hazaña juez de aguas por cuatro ańos. Puede pensarse que el Cabildo sentía la necesidad de afirmar

37 Acta del Cabildo del 29 de diciembre de 1631 (Lee y Bromley 1935-1962, 22: 107). En el 1630, el Cabildo fue mandado por el virrey, aunque todavía sin cedula, de votar "por juez de aguas poniendo los ojos en perssona de las partes y calidades que conbengan para el dicho ministerio y tal que sea desynteresada y selosa de administrar justiçia con rrectitud y ygualdad de partes y anpare y defienda en la suya a los yndios de estos balles que tan danificados son en el agua que tienen para sus sementeras debiendo ser los preferidos como naturales de esta tierra...» (Acta del Cabildo del 1 de enero de 1630 [Lee y Bromley 1935-1962, 21: 204]). Cerdán de Landa también comenta esta detalle e indica que el mandato fue repetido por otra real cédula del 16 de abril de 1636 (1793: 26).

${ }^{38}$ Acta del Cabildo del 1 de enero de 1646, AHML, LCL, volumen 24, ff. 67-67v. Otro ejemplo muestra que Pedro Albarez de Espinosa no podía ser elegido como juez de aguas por estar interesado en el agua de la acequia de Magdalena (Acta del Cabildo del 1 de enero de 1656, AHML, LCL, volumen 26, f. 21).

${ }^{39}$ Acta del Cabildo del 14 de enero de 1648, AHML, LCL, volumen 23, f. 226.

${ }^{40} \mathrm{Ib}$. 
la estabilidad del cargo. ${ }^{41}$ El texto del nombramiento confirmó que las responsabilidades del juez incluían la ciudad y el campo:

ser este ofiçio el mas neçessario dentro desta çiudad por lo que se devia atender y procurar la limpieza della de que pende la salud y puridad de los ayres. Y fuera della por la ygualdad en la rrepartiçion del agua para las haçiendas del campo y la breve execuçion en las limpias generales quando sse quita sin caussar con daño de las miesses y frutos las dilaçiones continuas en los tiempos mas apretados en orden a lo qual su ex. ${ }^{a}$ avia deseado en su gobierno. ${ }^{42}$

Un poco más de dos décadas después, en 1670, el virrey conde de Lemos (1667-1672) repitió esta misma sugerencia de separación, y el Cabildo volvió a discutir la idea de tener varios jueces de aguas: «Propuso su ex. ${ }^{a}$ que tenia reconosido ser muy necessario y conbiniencia de la ciudad el que hubiese tres Jueses de aguas, los dos que cuidasen de las asequias de la ciudad y el otro de las del campo». ${ }^{43}$ Esta vez el Cabildo siguió la sugerencia del virrey y nombró tres jueces en 1670 y 1671 . Pero, en 1672, retornó al sistema tradicional: «alegaron todos los capitulares a su ex. ${ }^{\text {a }}$ que dha votacion se suspendiesse por quanto eran mui conbeniente que el jusgado de aguas no estubiesse dividido en tantos si no que estubiesse en uno todo junto»..$^{44}$ En 1672, el regidor Antonio de Campos Marín de Benavides fue nombrado como único juez de aguas para los ámbitos rural y urbano. Sin embargo, en 1673 el Cabildo nombró dos jueces de aguas, uno para la ciudad y otro para el campo, aunque en 1674 volvieron al sistema tradicional de solo uno, sin explicación..$^{45}$

Estos frecuentes experimentos de dividir la jurisdicción del juez de aguas muestran dos patrones importantes. Primero, el Cabildo concebía

${ }^{41} \mathrm{El}$ único otro caso en que nombraron un juez de aguas por más que un año a la vez fue Antonio de Campos Benavides quien fue nombrado por cuatro años, entre $1660 \mathrm{y}$ 1663 (Acta del Cabildo del 1 de enero de 1660, AHML, LCL, volumen 26, f. 2).

${ }^{42}$ Acta del Cabildo del 15 de enero de 1648, AHML, LCL, volumen 23, ff. 226v-227v.

${ }^{43}$ Acta del Cabildo del 1 de enero de 1670, AHML, LCL, volumen 29, ff. 1-1v. Véase también Acta del Cabildo del 1 de enero de 1671, AHML, LCL, volumen 29, f. 53.

${ }^{44}$ Acta del Cabildo del 1 de enero de 1672, AHML, LCL, volumen 29, ff. 88-88v.

${ }^{45}$ En junio de aquel año se nombró un comisario especial para visitar a las acequias de Magdalena, Maranga y la Legua (Acta del Cabildo del 15 de junio de 1674, AHML, LCL, volumen 29, f. 226v). 
a la ciudad y el campo como conectados, «todo en uno», lo cual tiene sentido dado que todas las acequias salían del mismo río Rímac y algunas de ellas pasaban por la ciudad (zona urbana) antes de llegar a las sementeras. Segundo, esta definición de la conexión entre la ciudad y el campo, por tanto de integración jurisdiccional, fue mantenida y defendida por el Cabildo para conservar su poder y no tanto por razones prácticas relativas al manejo técnico del agua; como ya hemos indicado, los LCL muy pocas veces mencionan las aguas de riego.

Luego de todas estas discusiones y tensiones, la Real Audiencia siguió nombrando jueces de aguas para el campo de manera ocasional. Entre 1611 y 1711 , nombró cuatro jueces, cada uno por un año más o menos, aunque estos magistrados no figuran en la colección del Juzgado de Aguas del AGN. Ellos fueron: Fernando Arias de Ugarte (1611), Juan de Canseco (1626), Gaspar de Cuba y Arce (1686-1687) y Gonzalo Ramirez de Baquedano (1710-1711) (cuadro 1). Incluida en esta lista está la observación del Cabildo de 1687, que el virrey había dado comisión a un oidor de la Real Audiencia para hacer la repartición del agua de la acequia de Surco. ${ }^{46}$ En 1688 y 1689, el Cabildo eligió a regidores que también eran abogados de la Real Audiencia como jueces de aguas -Pedro de Azaña Solís y Palacio y Juan Sánchez Cascante-, aunque desconocemos el significado de este acto.

Fue solamente a partir de 1726 que la Real Audiencia empezó a nombrar un juez de aguas para el campo con cierta frecuencia, y solo entre los años 1761-1804 lo nombró de manera seguida (cuadro 2). Esta cronología indica una relación con las reformas borbónicas, pero la investigación de este tema está todavía por realizarse con mayor detalle. ${ }^{47}$

Durante esta época, y sobre todo en 1780, la Real Audiencia aplicó el mismo argumento antes usado por el Cabildo. El juez de aguas nombrado por esta institución — Mata Linares — pidió al virrey unir de manera permanente el cargo en una sola persona, en vez de mantener la división de juez de aguas de la ciudad nombrado por el Cabildo y juez de aguas

\footnotetext{
${ }^{46}$ Acta del Cabildo del 29 de julio de 1687, AHML, LCL, volumen 31, f. 147v.

47 Sobre este tema, véase Domínguez 2015.
} 
del campo designado por la Real Audiencia. Mata Linares sugirió que esta última se encargara del nombramiento: «la experiencia tiene vien acreditada la vtilidad que resulta de ser único el director en qualquier asunto». ${ }^{48}$ Además, argumentó que con un solo juez instalado varios años, en vez de cambiar cada año como era la costumbre del Cabildo, se podría "formar algún proyecto útil». ${ }^{49}$

La petición de Mata Linares no fue respondida y el debate continuó. En 1793, el famoso Cerdán de Landa, juez de aguas de la Real Audiencia, repitió los mismos argumentos que Mata Linares para mantener el Juzgado de Aguas bajo el control de una sola persona. Cerdán de Landa reconoció que el Cabildo había manejado «varios años la judicatura de aguas del campo juntamente con la de las acequias y pilas urbanas, con igual zelo y acierto», pero anotó también que

es no menos indubitable la elección libre, que ha exercido este Superior Gobierno para Juez de Aguas de los valles mismos en Señores Ministros de esta Real Audiencia, según han requerido, ó la necesidad de arreglos generales, ó la naturaleza de las ocurrencias sobrevenidas, ó la instancia de los Chacareros ó Hacendados. ${ }^{50}$

Cerdán de Landa enfatizó en los fundamentos legales para que los virreyes o presidentes de las reales audiencias nombraran al juez de aguas, sobre todo en los casos urgentes o importantes. Agregó que si bien en algunas ocasiones anteriores las ciudades y los cabildos habían hecho este trabajo, siempre se había informado a los virreyes y presidentes de sus acciones, y que en casos de urgencia los cabildos debían hacer «lo que

${ }^{48}$ Mata Linares, citado en Domínguez 2015; esta petición también está en AGN-CAJA1, Legajo 212, Cuaderno 44.

${ }^{49}$ Mata Linares, citado en Domínguez 2015.

${ }^{50}$ Cerdán de Landa 1793: 27. Para Cerdán, el juez de aguas debería trabajar en la distribución anual de "todas las aguas del Rímac», desde las bocatomas de Naña, Pariache, Carapongo, Huanchiguailas y Huachipa hasta Maranga, Magdalena y Legua. A diferencia de sus predecesores (jueces de aguas de la Real Audiencia) Cerdán, trabajó diez ańos seguidos y estuvo involucrado en cientos de casos. Como también sucedió con sus predecesores, durante su administración también hubo un juez de aguas nombrado por el Cabildo, que principalmente trabajó en la zona urbana, aunque no siempre. 
la Audiencia determinase». ${ }^{51}$ Básicamente, Cerdán de Landa sostenía que las audiencias deberían nombrar a los jueces de aguas, salvo en los casos en los que los cabildos ya tenían la costumbre de hacerlo. Aunque Cerdán de Landa describió la situación con más detalle que cualquier otra fuente, y aunque su opinión ha sido la más citada al respecto a la administración de agua, aquí se ve que él solamente estaba repitiendo y recopilando los debates, discusiones y peticiones ya hechos. En suma, queda claro que la ambigüedad sobre el cargo de juez de aguas y la definición de su jurisdicción se mantuvo por casi toda la época colonial.

\section{DISCUSIÓN Y CONCLUSIONES}

En el caso de la administración hidráulica, la distinción entre espacio rural y urbano fue un tema permanente de debate. Por razones físicas, administrar el agua dentro y fuera de la ciudad en conjunto tenía cierta lógica. El manejo integral de cuencas hidrográficas —o sea el gobierno coordinado de todos los usos del agua dentro de una cuenca- es considerado una de las maneras más prácticas de proteger, conservar y controlar recursos hídricos. El centro urbano de Lima se ubica relativamente cerca de donde concluye la cuenca del Rímac y es comprensible que el Cabildo quisiera mantener su control de las aguas en la parte más alta de la cuenca para asegurar el suministro de la ciudad. Además, teniendo en cuenta que habían campos agrícolas aguas abajo de la ciudad y que las acequias de riego de estos campos tenían que pasar por el espacio urbano primero, mantener una separación teórica entre aguas rurales y urbanas era complicado, sino imposible. De manera física, práctica y pragmática, administrar toda el agua de la cuenca como conjunto fue (y sigue siendo) un argumento razonable y racional.

Entonces, el debate no fue sobre la idea de juntar o dividir el agua, ya que era aceptado y aplicado el argumento de manejar las aguas rurales y urbanas juntas. El conflicto surgía de la ambigüedad respecto a que órgano del gobierno colonial debería controlar este recurso. Dos ambigüedades legales, iniciadas en el siglo XVI, dejaron el espacio ideal 
para el desarrollo de este conflicto. La primera, sobre el área reconocida como los términos de la ciudad de Lima, muestra que el territorio bajo jurisdicción del Cabildo se fue reduciendo, sobre todo al final del siglo XVI. El espacio perdido fue controlado por el virrey y la Real Audiencia. La segunda ambigüedad, respecto a qué órgano de gobierno podía nombrar al juez de aguas (especialmente para las aguas rurales), muestra que tanto el Cabildo como la Real Audiencia podían basar sus argumentos en mandatos legales establecidos. El Cabildo, con su costumbre de nombrar un juez de aguas cada ańo para el campo y la ciudad, reclamaba este derecho de forma presencial; es decir, poniendo uno de sus regidores en el puesto. No obstante, pese a que se nombraba un juez de aguas para el campo, parece que este personaje no realizó mucho trabajo en ese ámbito; falta documentación sobre sus obras y logros. La Real Audiencia buscaba insertar su propio juez de aguas en el vacío dejado por la inactividad del Cabildo y, durante el siglo XVII, de forma eventual, los jueces de aguas de la Real Audiencia ejecutaron varios trabajos importantes relacionados con el manejo del agua de riego. Durante el periodo borbónico, los jueces de la Real Audiencia tuvieron mayor presencia, aunque no siempre podían implementar las reformas propuestas. Tanto en el Cabildo (durante el siglo XVII) como en la Real Audiencia (a fines del siglo XVIII) se usaban los mismos argumentos, declarando que «no admite separación lo de la ciudad a lo del campo y es preciso este todo en uno». El desacuerdo fue sobre quién sería el único encargado. Parece que esto fue tema de rivalidad hasta 1921, cuando Augusto B. Leguía, dos veces presidente del Perú a inicios del siglo XX, centralizó el sistema de agua potable de Lima a nivel nacional. ${ }^{52}$

El tema de la administración y el control del agua es útil para investigar las relaciones urbano-rurales en la época colonial. Al estudiar la historia de este recurso, surgen otras preguntas importantes — todavía no analizadas — sobre esas relaciones. Podemos reconocer la rivalidad o conflicto

52 Durand 2015: 120. Luego, en 1981, el Servicio de Agua Potable y Alcantarillado de Lima (SEDAPAL) fue creado como la entidad responsable del agua de Lima, bajo la autoridad del Estado nacional y no la Municipalidad de Lima. 
entre la ciudad y el campo en otros aspectos del manejo de agua y de la producción agrícola en tres aspectos específicos. El primero es el dominio de la zona urbana sobre las fuentes de agua potable. Estudios previos han mostrado que el alcance hídrico urbano, o el área que una ciudad requiere (y, por tanto, domina) para su abastecimiento de agua potable, se extendía a la zona rural. En Lima, desde el momento en que se estableció el sistema de cañerías urbanas, el alcance hídrico de la zona urbana se extendía hasta los puquios de los alrededores rurales que antes se usaban para riego. Entonces, la zona urbana se apropió de esa agua rural para su abasto. ${ }^{53}$ Con el tiempo, este alcance hídrico se ha extendido más, incorporando zonas muy lejanas a la ciudad. Segundo, aquí hemos tratado el tema de la rivalidad entre el Cabildo y la Real Audiencia, pero todavía no se ha tocado el rol de las órdenes religiosas. Falta profundizar en el estudio de las relaciones entre hacendados, chacareros españoles (agricultores de pequeña escala), indígenas y órdenes religiosas, tanto como las asociaciones o conexiones de estos grupos con las instituciones de gobierno. Tercero, en relación con la producción agrícola, se ha podido identificar dos santos patrones de la agricultura en Lima: San Marcelo «el abogado de los frutos» ${ }^{54}$ y San Isidro, el patrón de los labradores en España y sus dominios coloniales. Esto genera más preguntas para futuras investigaciones. ¿Cómo se relacionaban los devotos de estos dos santos en las zonas rural y urbana de Lima? ¿Cómo intervenía el poder eclesiástico en las disputas descritas? En cada uno de los tres aspectos mencionados se pueden observar las rivalidades entre grupos sociales y políticos en las zonas urbana y rural.

A modo de conclusión, conviene presentar una última observación del Tratado General de Cerdán de Landa: «Esta amable Capital ha crecido

\footnotetext{
53 Bell 2015: 97-98.

${ }^{54}$ Acta del Cabildo del 14 de julio de 1625 (Lee y Bromley 1935-1962, 20: 146). Otras versiones de su título incluyen: "patrón de los frutos» (Acta del Cabildo del 8 de julio de 1625 [Lee y Bromley 1935-1962, 20: 138]), «abogado de las mieses» (Acta del Cabildo del 9 de agosto de 1632 [Lee y Bromley 1935-1962, 22: 188]), "abogado de los labradores» (Acta del Cabildo del 6 de julio de 1652, AHML, LCL, volumen 25, ff. 194v-195), y "patrón y abogado de esta ciudad para las lluvias» (Acta del Cabildo del 12 de junio de 1646, AHML, LCL, volumen 24, f. 99v).
} 
mucho en moradores y extensión respecto de la que tenía en los 40 o 50 años últimos: y esta consideración sola inclina a concebir no ser ya tiempo de mantenerla sobre los limitados principios de comodidad que la fue proporcionada en los antiguos». ${ }^{55}$ Sin prestar mucha atención a las posibles comparaciones que se podrían establecer entre la situación descrita y el siglo XXI, cabe comentar que Cerdán de Landa basaba sus argumentos en ideas y leyes antiguas, originadas en el siglo XVI y XVII. Aunque este personaje posiblemente fue el juez de aguas nombrado por la Real Audiencia con más experiencia, conocimiento e interés en la buena gestión de su cargo, él tampoco podía escapar a su contexto. Es decir, Cerdán de Landa trabajaba en un medio urbano caracterizado por los conflictos, la desigualdad, la corrupción y el desorden provocados por una serie de fundamentos legales ambiguos, y constantes pugnas entre los dueños y los usuarios de la tierra y los órganos de gobierno. $\mathrm{Su}$ valioso testimonio, que ha servido de entrada para comprender la situación hidráulica colonial tardía, debe ser siempre leído partiendo desde ese entramado social y político.

Cuadro 1. Jueces de aguas de la Real Audiencia, 1611-1711 ${ }^{56}$

\begin{tabular}{ll}
\hline Ańo & Juez de aguas de la Real Audiencia \\
\hline 1611 & Fernando Arias de Ugarte \\
1621 & Juan de Canseco \\
1686 & Gaspar de Cuba y Arce \\
1687 & Gaspar de Cuba y Arce \\
1710 & Gonzalo Ramírez de Baquedano \\
1711 & Gonzalo Ramírez de Baquedano \\
\hline
\end{tabular}

Fuentes: Catálogo del Juzgado de Aguas del AGN; Cerdán de Landa 1793.

\footnotetext{
55 Cerdán de Landa 1793: 20.

${ }^{56}$ Los jueces de aguas de la Real Audiencia fueron funcionarios — mayormente oidores o abogados — de esta institución.
} 


\section{Cuadro 2. Jueces de aguas de la Real Audiencia, 1726-1804 ${ }^{57}$}

\begin{tabular}{ll}
\hline Ańo & Juez de aguas de la Real Audiencia \\
\hline 1726 & Francisco Xavier de Salazar \\
1727 & n/d, [Francisco Xavier de Salazar] \\
1728 & Francisco Xavier de Salazar \\
$1729-1736$ & n/d, [Francisco Xavier de Salazar] \\
1737 & Marqués de Casa-Concha \\
$1738-1742$ & n/d, [Marqués de Casa-Concha] \\
1743 & Juan Gutiérrez de Arce \\
1744 & n/d, [Juan Gutiérrez de Arce] \\
1745 & Manuel Antonio de Borda \\
$1746-1748$ & n/d, [Manuel Antonio de Borda] \\
1749 & Manuel de Gorena \\
$1750-1760$ & n/d, [Manuel de Gorena] \\
1761 & Alfonso Carrion \\
1762 & n/d, [Alfonso Carrion] \\
1763 & Pedro Brabo de Catilla \\
1764 & Bartolomé de Azańa \\
1765 & n/d, [Bartolomé de Azaña] \\
1766 & Domingo de Orrantia \\
1767 & Manuel Isidro de Mirones \\
1768 & [Manuel Isidro de Mirones] \\
$1769-1771$ & n/d, [Manuel Isidro de Mirones] \\
1772 & [Manuel de Mansilla Arias de Saavedra] \\
$1773-1777$ & Pedro Antonio de Echeverz (1775, n/d, [Pedro Antonio de Echeverz]) \\
1778 & Pedro Antonio de Echeverz, Joseph Cabeza Enriquez \\
1779 & José Cabeza Enríquez, Benito de la Mata Linares \\
1780 & Benito de la Mata Linares \\
1781 & Benito de la Mata Linares, Manuel Antonio de Arredondo \\
1782 & Manuel Antonio de Arredondo \\
1783 & Manuel Antonio de Arredondo, Fernando Márquez de la Plata \\
$1784-1794$ & Ambrosio Cerdán y Pontero \\
$1795-1804$ & Manuel Pardo Rivadeneyra \\
\hline &
\end{tabular}

Fuentes: Catálogo del Juzgado de Aguas del AGN; Cerdán de Landa 1793.

${ }^{57}$ La Real Audiencia solo nombró jueces con regularidad entre los años 1726-1804. En ese periodo, cuando se indica «n/d», es probable que luego de que se nombrara un juez, él mismo haya seguido en el cargo, pero no tenemos documentación para sustentar esta propuesta. Desconocemos que pasó con los nombramientos de la Real Audiencia después de 1804. 


\section{BIBLIOGRAFÍA}

Bell, Martha G. 2013. The governance of food technology and environmental resource flows: Connecting mills, water, wheat, and people in colonial Lima, Peru (1535-1700). Tesis de Doctorado. University Park, Pennsylvania: Pennsylvania State University.

2015. «Agua y poder colonial: ciclos, flujos y procesiones en el manejo hidráulico urbano en Lima durante el siglo XVII». Boletín del Instituto Riva-Agüero. Núm. 37: 75-121.

Borah, Woodrow. 1985. El Juzgado General de Indios en la Nueva España. México, D. F.: Fondo de Cultura Económica.

Cerdán de Landa y Simón Pontero, Ambrosio. 1793. Tratado general sobre las aguas que fertilizan los valles de Lima. Publicado en el Mercurio Peruano por don Ambrosio Cerdan de Landa, Simon Pontero, del consejo de S. M., oydor en la Real Audiencia de Los Reyes, individuo de la Real Academia Española de la Historia, y de la Sociedad de Amantes del País. Lima: Imprenta Real de los Niños Expósitos de Lima. Disponible en: $<$ https://archive.org/details/tratadogeneralso00cerd>.

Cieza de León, Pedro. 1984. La crónica del Perú. Edición de Manuel Ballesteros. Madrid: Historia 16.

Cogorno, Gilda. 2015. Agua e hidráulica urbana de Lima: espacio y gobierno, 1535-1596. Lima: Instituto Riva-Agüero y Pontificia Universidad Católica del Perú.

Domínguez, Nicanor. 1988. «Aguas y legislación en los Valles de Lima: El Repartimiento de 1617». Boletín del Instituto Riva-Agüero. Núm. 15: 119-154.

2015. «Aguas y reformación en los Valles de Lima: El proyecto de Ordenanzas del oidor Mata Linares de 1780». Boletín del Instituto RivaAgüero. Núm. 38. En prensa.

Durand, Mathieu. 2015. Residuos y desagües: geografía limeña. Lima: Instituto Francés de Estudios Andinos.

Lee, Bertram y Juan Bromley (eds.). 1935-1962 [1534-1637]. Libros de Cabildos de Lima. Prólogo de José de la Riva-Agüero. Lima: Sanmartí, 23 volúmenes.

Lohmann, Guillermo. 2001. El Corregidor de indios en el Perú bajo los Austrias. Lima: Pontificia Universidad Católica del Perú.

Moore, John Preston. 1954. The Cabildo in Peru under the Hapsburgs. Durham: Duke University Press. 
Narváez, Joaquín. 2013. Pre-colonial irrigation and settlement patterns in three artificial valleys in Lima - Perú. Tesis de doctorado en Arqueología. Calgary, Alberta: University of Calgary.

Recopilación de leyes de los reynos de las Indias. 1791. Madrid: Viuda de Joaquín de Ibarra, 3 vols.

Solano, Francisco de. 1996. Normas y Leyes de la Ciudad Hispanoamericana (1492-1600). Madrid: Consejo Superior de Investigaciones Científicas Centro de Estudios Históricos, 2 vols.

Toledo, Francisco de. 1986-1989. Disposiciones Gubernativas para el Virreinato del Perú, 1575-1580. Transcripción de María Justina Sarabia Viejo e introducción de Guillermo Lohmann Villena. Sevilla: Escuela de Estudios Hispano-Americanos, 2 vols.

Fecha de recepción: 15/IX/2015

Fecha de aceptación: 18/III/2016 